\title{
Tocopherol Content as Affected by Different Sowing Dates and its Correlation with Other Quality Traits in Soybean [Glycine max (L.) Merrill]
}

\author{
Kuldeep Kaur*, B.S. Gill, Sunita Sharma and Ashutosh Kushwah
}

Department of Plant Breeding and Genetics, Punjab Agricultural University, Ludhiana-141004, India

*Corresponding author

\begin{tabular}{|c|c|}
\hline & A B S T R A C T \\
\hline Keywords & \multirow{4}{*}{$\begin{array}{l}\text { To study the effect of different temperature and photoperiod regimes on tocopherol } \\
\text { content, seventeen photo and thermo tolerant soybean genotypes were planted under } \\
\text { three planting dates viz., March 1(D1), June } 5 \text { (D2) and August } 7 \text { (D3). Analysis of } \\
\text { variance revealed significant differences for genotypes, environments and genotype x } \\
\text { environment interaction for tocopherol content. It was highest (average of } 850 \mathrm{ppm} \\
\text { with range of 588-1255 ppm) in case of June sowing where grain filling stage was } \\
\text { exposed to moderate temperature and photoperiod conditions. Exposure of seed filling } \\
\text { stage to high (March sowing) or low (August sowing) temperatures and photoperiods } \\
\text { reduced tocopherol concentrations. Correlation analysis revealed that tocopherol } \\
\text { content was significantly and negatively correlated with oil content in March and } \\
\text { August sowings. Identification of genotypes having high tocopherol in each sowing } \\
\text { signified the role of genetic background along with role of growing environment in } \\
\text { tocopherol synthesis. }\end{array}$} \\
\hline $\begin{array}{l}\text { Glycine max, } \\
\text { Sowing dates, } \\
\text { GxE interaction, } \\
\text { Tocopherol } \\
\text { content, } \\
\text { Correlations. }\end{array}$ & \\
\hline Article Info & \\
\hline $\begin{array}{l}\text { Accepted: } \\
\text { 17 April } 2017 \\
\text { Available Online: } \\
10 \text { May } 2017\end{array}$ & \\
\hline
\end{tabular}

\section{Introduction}

Tocopherols are important bioactive constituents of plant seed oils including soybean [Glycine $\max$ (L.) Merrill] oil. Soybean contains about $20 \%$ of oil and tocopherols are about $1.5 \%$ of the oil (Clemente and Cahoon, 2009), the tocopherol concentration in soybean range from 10001500 ppm (Kim et al., 2007). Its nutritional value was recognized more than 90 years ago by Evans and Bishop (1922). Intake of tocopherols has shown several human health benefits such as the reduction of heart and cardiovascular disease, cancer and antiinflammatory properties (Liu, 2000; Devaraj and Jialal, 2000; Boschin and Arnoldi, 2011; Rizvi et al., 2014).
This is mostly because tocopherols are antioxidants and have a physiological role to protect unsaturated lipids against free radicals and oxidation, which are natural processes occuring in biological systems and vegetable oil products (Rizvi et al., 2014).

The antioxidant property of oil is influenced by tocopherol concentration present in oil. Thus, tocopherols contribute to both the nutritional value of seeds and the oxidative stability of oil. Tocopherols are also involved in regulation of expression of certain genes. The multiple roles of tocopherols in living organism stimulates the interest of research in this area and enhancing tocopherol content in 
soybean seeds has become a new and an important objective.

Environmental factors such as drought (Britz et al., 2008) and agronomic practices including planting date, row spacing and planting density (Seguin et al., 2010) are known to influence tocopherol levels. Tocopherol content has been shown to differ over environments characterized by different temperature and photoperiod (Whent et al., 2009). Studies showed that low temperatures decreases total tocopherol content and higher concentrations of tocopherols are formed under warmer conditions (Almonor et al., 1998). Genotype x environment interation for tocopherols has also been reported by Ujiie et al., 2005; Shaw et al., 2015; Sharma and Goyal, 2015). These studies are based on limited environmental conditions i.e. temperature and photoperiod. Therefore, present investigation was conducted with photo and thermo tolerant genotypes to study the variation in tocopherol content under very wide environmental conditions characterized by different temperature and photoperiod regimes created by manipulating the sowing dates. Information regarding association of tocopherol content with other nutritional and antinutritional components is also scarce in soybean. Thus, correlations of tocopherol content with other quality parameters (protein, oil and fatty acid composition) under different environmental conditions were also studied.

\section{Materials and Methods}

\section{Soybean genotypes and field evaluation}

Seventeen photo and thermo tolerant soybean genotypes (Table 1) were grown at the Pulses Research area of Department of Plant Breeding and Genetics, Punjab Agricultural University, Ludhiana, India under three different planting dates viz., March 1(D1),
June 5 (D2) and August 7 (D3) to expose seed development stage to varying temperature and photoperiod conditions. The response of genotypes to increasing day length and temperature was studied by growing soybean genotypes in March. The first fortnight of June is recommended sowing time of soybean for the region. The response of genotypes to shorter day length and falling temperature as compared to the normal sowing conditions (June) were studied by sowing in August. The soybean genotypes were sown in randomized complete block design with three replications in each of three sowing dates. The genotypes were planted in four rows of $3 \mathrm{~m}$ length with row to row spacing of $22.5 \mathrm{~cm}$ and plant to plant spacing of $5 \mathrm{~cm}$ within the rows. The recommended dose of fertilizers were applied i.e. 4 tonnes of Farm yard manure (FYM) per acre, $12.5 \mathrm{~kg}$ of $\mathrm{N}\left(28 \mathrm{~kg}\right.$ of urea) and $32 \mathrm{~kg} \mathrm{P}_{2} \mathrm{O}_{2}(200 \mathrm{~kg}$ single superphosphate) at time of sowing. Four irrigations were applied and weeds were controlled by pre-germination spray of Stomp 30EC (pendimethalin) @ 600ml per acre followed by two hand weedings at 20 and 40 days after sowing. Crop was harvested and threshed manually at maturity.

\section{Tocopherol analysis}

The tocopherol analysis was done as per method of Kayden et al., 1973. Freshly harvested seeds $(10 \mathrm{~g})$ were dried and cleaned to free them from extraneous matter. Out of this, $100 \mathrm{mg}$ of seeds were crushed in a pestle mortar in $3 \mathrm{ml}$ of ethanol. The mixture was centrifuged at $4000 \mathrm{rpm}$ for 10 minutes. 1.2 $\mathrm{ml}$ each of supernatant, standard vitamin $\mathrm{E}$ and absolute alcohol were pipetted out in glass stoppened centrifuge tubes marked as test, standard and blank, respectively. $1.2 \mathrm{ml}$ of distilled water was added to all the three tubes. The tubes were stoppened and vortexed thoroughly. Then, $1.2 \mathrm{ml}$ of xylene was added and vortexed for two minutes. The tubes were 
centrifuged at $5000 \mathrm{rpm}$ for 5 minutes. From each tube $0.8 \mathrm{ml}$ of xylene layer was carefully pipetted into appropriately labelled stoppered glass test tubes containing $0.4 \mathrm{ml}$ of bathophenanthroline reagent and mixed thoroughly. $0.4 \mathrm{ml}$ ferric chloride reagent followed by $0.4 \mathrm{ml}$ of orthophosphoric acid was added. The contents in the tube were mixed thoroughly after adding each reagent. Absorbance of test, standard and blank was read at $536 \mathrm{~nm}$ against xylene as reference within 30 seconds. Contact of samples with sunlight was avoided. Total tocopherol content was calculated as:

$\mathrm{A}_{\mathrm{T}} \mathrm{X}$ concentration of standard $\mathrm{x}$ total volume of sample $(3 \mathrm{ml}) \mathrm{x} \%$ oil

Total Tocopherol $=$

$\mathrm{A}_{\mathrm{S}} \mathrm{X}$ volume of test taken $\mathrm{x}$ weight of tissue $(\mathrm{g})$

Where, $\mathrm{A}_{\mathrm{T}}=$ Absorbance of test Absorbance of blank and $A_{S}=$ Absorbance of standard - Absorbance of blank

Total tocopherol estimates were obtained in $\mathrm{mg} / \mathrm{g}$ which was converted into ppm.

\section{Analysis of other seed components}

Seed samples were grounded into flour by passing through a 50 mesh screen in Cemo Tech 1090 M. (Tecator Sweden) electric grinder (Foss). Powdered samples were used for further analysis. Fatty acid composition (palmitic (16:0), stearic (18:0), oleic (18:1), linoleic (18:2) and linolenic acid 18:3) in each soybean genotype for all three sowing dates was determined using gas liquid chromatography (model NUCON 5700, AIMIL India). Protein content was determined by macro Kjeldahl method (AOAC 2000) and oil content was estimated through solvent extraction system by using the instrument Socsplus AS Series 4.

\section{Statistical analysis}

The analysis of variance was carried out for individual sowing dates and over sowing dates using SAS PROG. Correlations of tocopherol content with protein, oil and fatty acids (palmitic, stearic, oleic, linoleic and linolenic acid were calculated for each date of sowing separately.

\section{Results and Discussion}

Analysis of variance for individual environments revealed significant differences between the genotypes for tocopherol content under March (D1), June (D2) and August (D3) sowing dates (data not shown). Results of pooled analysis of variance over the three environments (sowing dates) also showed that genotypes, sowing dates and genotype $\mathrm{x}$ sowing date interactions were significant $(\mathrm{P}$ $<0.01$ ) for tocopherol content (data not shown). Highly significant variance due to interaction between sowing dates and genotypes suggested that response of genotypes was not uniform in direction and magnitude. Whent et al., (2009) also reported significant environment effect and genotype and environment $\left(\begin{array}{lll}G & \mathrm{x} & \mathrm{E}\end{array}\right)$ interaction for tocopherols.

Table 1 shows mean values of tocopherol content for each of the seventeen genotypes in all three sowing dates and overall mean over sowing dates. Mean values for other quality parameters i.e. protein, oil and fatty acids are also given (Tables 1 and 2). Tocopherol content was highest in case of D2 with average of $850 \mathrm{ppm}$ and range of 588-1255 ppm. SL (E) 1 had the highest tocopherol content. Mean for D1 sowing was 770 ppm which varied from $530 \mathrm{ppm}$ (SL (E) 41) to 1223 ppm (SL (E) 38) while mean tocopherol content in case of D3 was 740 ppm with 
highest value of 992 ppm shown by the genotype SL (E) 20 and lowest value of 457 ppm was recorded for genotype, SL (E) 32. As all the genotypes interacted differently with sowing dates, hence, ranking of genotypes changed in each sowing date.

Study showed that most of genotypes produced high tocopherol content when seed maturation took place at moderate temperature and photoperiod as in D2 i.e. recommended plating time for soybean. The tocopherol content of eight genotypes, out of 17 genotypes was high under D2 (June) sowing. Six genotypes recorded highest value in D1 (March) sowing where seed development coincided with high temperature and photoperiod. Remaining three genotypes produced highest concentrations of tocopherol content in D3 (August) sowing i.e. when reproductive phase fall under low temperature and photoperiod. The genotype, MACS 330 had relatively stable tocopherol content over environments as compared to other genotypes. These results are similar to the findings of Almonor et al., 1998 that showed that low temperatures decreases total tocopherol content, however, contrary to their results that higher concentration of tocopherols formed under warmer conditions. As in our study warmer temperatures during final days of seed filling stage also reduced tocopherol content. Britz et al., (2008) observed that total tocopherols did not change much under varying temperatures.

Correlations of tocopherol content with protein, oil and five fatty acids viz., stearic, palmitic, oleic, linoleic and linolenic acids were estimated separately for all the sowing dates (Table 3). These characters were found to show a range of mild to strong associations with tocopherol under some of the environments i.e. sowing dates. Results showed highly significant and negative correlations of tocopherol with oil content in
D1 ( $\left.\mathrm{r}=-0.42^{* *}\right)$ and D3 ( $\left.\mathrm{r}=-0.44^{* *}\right)$ and nonsignificant association in D2. As tocopherol content is synthesized via pathway which is different from oil synthesis (Bramley et al., 2000), the correlations are probably not due to biosynthesis of these components. The negative correlation of tocopherols with oil content in D1 and D3 and non-significant correlation in D2 is because oil content was stable over environments and tocopherol content was low in D1 and D3 as compared to D2. Protein content showed positive correlation with tocopherol in D3 sowing $(r=$ $0.35^{*}$ ) while in D1 and D2, it was nonsignificant.

Among fatty acids, tocopherol showed positive association with stearic acid in D2 $\left(\mathrm{r}=0.32^{*}\right)$, linoleic acid in D2 $(\mathrm{r}=0.32 *)$ and D3 $\left(r=0.38^{* *}\right)$ while it was significantly and negatively correlated with oleic acid in D1 $(r=$ $-0.31 *)$ and linolenic acid in D3 $(\mathrm{r}=-0.52 * *)$. Positive correlation of tocopherol with linoleic acid as in D2 and D3 is supported by many studies (Mounts et al., 1996; Almonor et al., 1998; Dolde et al., 1999; McCord et al., 2004; Rani et al., 2007).

This positive correlation suggests that increase in tocopherol content will increase the proportion of polyunsaturated fatty acid i.e. linoleic acid in soybean oil. A negative correlation between tocopherols and linolenic acid has also been earlier reported (Mounts $e t$. al. 1996).

Selection of genotypes with high tocopherol content along with reduced linolenic acids are desirable to increase stability of soybean oil. In the present study, non significant association has been observed between tocopherol content and palmitic acid which is contrary to the earlier reports (Mounts et al., 1996; Scherder et al., 2006) where negative correlation has been observed between tocopherol content and palmitic acid. 
Table.1 Tocopherol, protein and oil content of 17 soybean genotypes under three different dates of sowing

\begin{tabular}{|c|c|c|c|c|c|c|c|c|c|c|c|c|c|}
\hline \multirow[t]{2}{*}{ S. No. } & \multirow[t]{2}{*}{ Genotypes } & \multicolumn{3}{|c|}{ Tocopherol content (ppm) } & \multirow[b]{2}{*}{ Mean } & \multicolumn{3}{|c|}{ Protein index $(\%)$} & \multirow[b]{2}{*}{ Mean } & \multicolumn{4}{|c|}{ Oil content $(\%)$} \\
\hline & & D1 & D2 & D3 & & D1 & D2 & D3 & & D1 & D2 & D3 & Mean \\
\hline 1 & SL (E) 1 & 595 & 1255 & 597 & 816 & 37.0 & 39.9 & 34.8 & 37.2 & 22.1 & 22.2 & 22.1 & 22.1 \\
\hline 2 & SL (E) 14 & 677 & 646 & 966 & 763 & 38.3 & 40.8 & 37.2 & 38.8 & 21.8 & 21.5 & 21.3 & 21.5 \\
\hline 3 & $\mathrm{SL}$ (E) 14A & 625 & 990 & 731 & 782 & 35.8 & 38.9 & 32.1 & 35.6 & 22.4 & 21.8 & 21.7 & 22.0 \\
\hline 4 & SL (E) 18 & 7.99 & 6.26 & 617 & 681 & 33.8 & 37.3 & 33.9 & 35.0 & 21.4 & 21.4 & 21.4 & 21.4 \\
\hline 5 & SL (E) 20 & 902 & 1026 & 992 & 973 & 37.0 & 41.1 & 37.2 & 38.4 & 21.3 & 20.8 & 21.4 & 21.2 \\
\hline 6 & SL (E) 21 & 859 & 786 & 679 & 775 & 36.3 & 38.7 & 34.8 & 36.6 & 21.0 & 20.5 & 21.2 & 20.9 \\
\hline 7 & SL (E) 27 & 720 & 1152 & 734 & 869 & 35.8 & 41.3 & 34.3 & 37.1 & 21.1 & 20.7 & 21.1 & 21.0 \\
\hline 8 & SL (E) 28 & 751 & 598 & 778 & 709 & 37.5 & 40.4 & 34.3 & 37.4 & 22.4 & 22.0 & 22.1 & 22.2 \\
\hline 9 & SL (E) 32 & 553 & 838 & 457 & 616 & 36.4 & 40.6 & 34.3 & 37.1 & 22.5 & 22.3 & 22.2 & 22.3 \\
\hline 10 & SL (E) 38 & 1223 & 1040 & 958 & 1074 & 39.1 & 40.1 & 34.9 & 38.0 & 21.6 & 21.2 & 21.1 & 21.3 \\
\hline 11 & SL (E) 39 & 1010 & 781 & 773 & 855 & 34.3 & 37.6 & 33.8 & 35.2 & 21.1 & 20.5 & 21.1 & 20.9 \\
\hline 12 & SL (E) 40 & 1060 & 588 & 781 & 810 & 37.5 & 41.1 & 34.1 & 37.6 & 21.2 & 20.6 & 21.2 & 21.0 \\
\hline 13 & SL (E) 41 & 530 & 723 & 728 & 660 & 36.0 & 38.7 & 34.6 & 36.4 & 21.7 & 21.9 & 21.8 & 21.8 \\
\hline 14 & SL (E) 42 & 686 & 931 & 845 & 821 & 33.3 & 40.9 & 34.5 & 36.2 & 21.8 & 20.9 & 21.1 & 21.3 \\
\hline 15 & SL (E) 44 & 830 & 747 & 697 & 758 & 37.1 & 41.7 & 35.1 & 38.0 & 22.2 & 22.5 & 22.3 & 22.3 \\
\hline 16 & SL (E) 45 & 583 & 950 & 6.62 & 732 & 39.1 & 40.0 & 35.6 & 38.2 & 21.6 & 21.3 & 21.5 & 21.4 \\
\hline \multirow[t]{4}{*}{17} & MACS 330 & 653 & 774 & 669 & 699 & 37.5 & 38.3 & 34.2 & 36.7 & 21.6 & 21.6 & 21.4 & 21.5 \\
\hline & CD & 0.7 & 0.6 & 0.4 & & 1.9 & 1.8 & NS* & & 0.6 & 0.4 & 0.5 & \\
\hline & Mean & 770 & 850 & 740 & & 36.6 & 39.8 & 34.7 & & 21.7 & 21.4 & 21.5 & \\
\hline & Range & $530-1223$ & 588-1255 & 457-992 & & 33.3-39.1 & 37.3-41.7 & 32.1-37.2 & & $21.0-22.5$ & $20.5-22.5$ & 21.1-22.3 & \\
\hline
\end{tabular}

$\mathrm{CD}$, critical difference, $* \mathrm{NS}$, non significant at 0.05 level of probability, 
Table.2 Fatty acid composition of 17 soybean genotypes under three different dates of sowing

\begin{tabular}{|c|c|c|c|c|c|c|c|c|c|c|c|c|c|c|c|c|c|c|c|c|c|}
\hline \multirow{3}{*}{$\begin{array}{c}\text { S. } \\
\text { No. }\end{array}$} & \multirow[t]{3}{*}{ Genotypes } & \multicolumn{20}{|c|}{ Fatty acids (\%) } \\
\hline & & \multicolumn{4}{|c|}{ Palmitic acid } & \multicolumn{4}{|c|}{ Stearic acid } & \multicolumn{4}{|c|}{ Oieic acid } & \multicolumn{4}{|c|}{ Linoleic acid } & \multicolumn{4}{|c|}{ Linolenic acid } \\
\hline & & D1 & D2 & D3 & Mean & D1 & D2 & D3 & Mean & D1 & D2 & D3 & Mean & D1 & D2 & D3 & Mean & D1 & D2 & D3 & Mean \\
\hline 1 & $\mathrm{SL}(\mathrm{E}) 1$ & 10.8 & 10.5 & 9.9 & 10.4 & 3.7 & 3.3 & 3.8 & 3.6 & 38.4 & 22.3 & 21.6 & 27.4 & 51.0 & 54.0 & 55.8 & 53.6 & 6.9 & 12.9 & 13.0 & 10.9 \\
\hline 2 & SL(E)14 & 10.5 & 7.9 & 9.9 & 9.4 & 3.7 & 3.1 & 3.7 & 3.5 & 34.8 & 23.9 & 19.1 & 25.9 & 54.4 & 60.5 & 69.3 & 61.4 & 7.3 & 11.3 & 12.1 & 10.2 \\
\hline 3 & SL(E)14A & 13.0 & 8.6 & 8.9 & 10.2 & 4.1 & 2.5 & 2.5 & 3.0 & 33.8 & 34.4 & 20.9 & 29.7 & 52.8 & 48.5 & 55.7 & 52.3 & 8.4 & 8.4 & 12.0 & 9.6 \\
\hline 4 & SL(E)18 & 8.0 & 8.8 & 9.3 & 8.7 & 2.3 & 2.6 & 2.9 & 2.6 & 30.4 & 26.3 & 18.9 & 25.2 & 61.4 & 54.5 & 71.7 & 62.5 & 9.6 & 9.6 & 15.0 & 11.4 \\
\hline 5 & $\mathrm{SL}(\mathrm{E}) 20$ & 9.7 & 10.1 & 12.1 & 10.6 & 3.3 & 3.8 & 4.0 & 3.7 & 36.8 & 27.7 & 26.5 & 30.3 & 58.4 & 61.0 & 58.9 & 59.4 & 7.1 & 5.8 & 5.7 & 6.2 \\
\hline 6 & $\mathrm{SL}(\mathrm{E}) 21$ & 12.1 & 13.3 & 14.3 & 13.2 & 3.9 & 4.1 & 4.2 & 4.1 & 38.9 & 28.0 & 22.8 & 29.9 & 48.5 & 58.5 & 62.7 & 56.6 & 6.8 & 9.3 & 12.4 & 9.5 \\
\hline 7 & SL(E)27 & 10.2 & 10.4 & 11.2 & 10.6 & 3.4 & 3.5 & 3.8 & 3.6 & 31.1 & 19.4 & 30.3 & 26.9 & 58.6 & 62.0 & 54.6 & 58.4 & 9.0 & 12.2 & 6.6 & 9.3 \\
\hline 8 & SL(E)28 & 5.8 & 12.0 & 7.4 & 8.4 & 1.9 & 3.0 & 2.4 & 2.4 & 40.3 & 34.4 & 21.8 & 32.2 & 53.7 & 53.4 & 70.5 & 59.2 & 6.0 & 8.7 & 11.7 & 8.8 \\
\hline 9 & SL(E)32 & 10.1 & 9.9 & 8.5 & 9.5 & 3.6 & 3.5 & 3.3 & 3.5 & 35.0 & 19.0 & 21.8 & 25.3 & 44.6 & 51.8 & 52.0 & 49.5 & 5.7 & 11.7 & 12.5 & 10.0 \\
\hline 10 & SL(E)38 & 12.5 & 11.4 & 10.6 & 11.5 & 4.1 & 3.7 & 3.3 & 3.7 & 32.1 & 36.0 & 22.7 & 30.3 & 55.2 & 52.5 & 73.0 & 60.2 & 9.3 & 6.9 & 5.4 & 7.2 \\
\hline 11 & SL(E)39 & 7.6 & 6.3 & 11.6 & 8.5 & 3.1 & 2.8 & 3.7 & 3.2 & 36.3 & 21.6 & 29.3 & 29.1 & 55.9 & 56.5 & 55.7 & 56.0 & 7.0 & 15.6 & 5.9 & 9.5 \\
\hline 12 & SL(E)40 & 14.0 & 11.3 & 12.6 & 12.6 & 4.3 & 3.3 & 3.4 & 3.7 & 34.0 & 34.3 & 27.3 & 31.9 & 51.8 & 34.2 & 56.4 & 47.5 & 8.4 & 8.7 & 6.0 & 7.7 \\
\hline 13 & SL(E)41 & 8.3 & 8.7 & 9.4 & 8.8 & 2.8 & 2.6 & 3.2 & 2.9 & 32.2 & 26.3 & 22.0 & 26.8 & 59.7 & 54.5 & 56.0 & 56.7 & 9.4 & 10.3 & 12.1 & 10.6 \\
\hline 14 & SL(E)42 & 6.9 & 10.3 & 8.9 & 8.7 & 2.2 & 3.5 & 2.9 & 2.9 & 30.6 & 16.4 & 21.7 & 22.9 & 52.4 & 63.0 & 67.4 & 60.9 & 6.1 & 5.5 & 5.7 & 5.8 \\
\hline 15 & SL(E)44 & 7.6 & 8.2 & 12.6 & 9.5 & 2.9 & 2.9 & 3.5 & 3.1 & 38.9 & 24.0 & 25.1 & 29.3 & 53.3 & 57.0 & 55.0 & 55.1 & 7.0 & 10.6 & 6.1 & 7.9 \\
\hline 16 & SL(E)45 & 9.9 & 9.9 & 8.8 & 9.5 & 3.6 & 3.3 & 2.8 & 3.2 & 31.0 & 21.8 & 19.0 & 23.9 & 47.1 & 57.3 & 72.0 & 58.8 & 5.6 & 13.8 & 13.8 & 11.1 \\
\hline 17 & MACS330 & 9.3 & 7.6 & 7.2 & 8.0 & 3.4 & 3.1 & 3.3 & 3.3 & 32.0 & 32.7 & 21.8 & 28.8 & 58.6 & 51.0 & 51.1 & 53.6 & 9.1 & 8.5 & 11.6 & 9.7 \\
\hline & CD & 0.6 & 0.3 & 0.3 & & 0.4 & 0.3 & 0.3 & & 0.6 & 0.3 & 0.3 & & 0.3 & 0.3 & 0.4 & & 0.6 & 0.7 & 0.6 & \\
\hline & Mean & 9.8 & 9.7 & 10.2 & & 3.3 & 3.2 & 3.3 & & 34.5 & 26.3 & 23.1 & & 54.0 & 54.7 & 61.2 & & 7.6 & 9.9 & 9.8 & \\
\hline & Range & $\begin{array}{c}5.8- \\
14.0\end{array}$ & $\begin{array}{l}6.3- \\
13.3\end{array}$ & $\begin{array}{l}7.2- \\
14.3\end{array}$ & & $\begin{array}{l}1.9- \\
4.3\end{array}$ & $\begin{array}{c}2.5- \\
4.1\end{array}$ & $\begin{array}{l}2.4- \\
4.2\end{array}$ & & $\begin{array}{c}30.4- \\
40.3\end{array}$ & $\begin{array}{l}16.4- \\
36.0\end{array}$ & $\begin{array}{c}19.0- \\
30.3\end{array}$ & & $\begin{array}{c}44.6- \\
61.4\end{array}$ & $\begin{array}{c}34.2- \\
63.0\end{array}$ & $\begin{array}{c}51.1- \\
73.0\end{array}$ & & $\begin{array}{l}5.6- \\
9.6\end{array}$ & $\begin{array}{c}5.5- \\
15.6\end{array}$ & $\begin{array}{l}5.4- \\
15.0\end{array}$ & \\
\hline
\end{tabular}

Table.3 Correlation coefficients between tocopherol content and protein, oil, palmitic, stearic, oleic, linoleic and linolenic acid

\begin{tabular}{|c|c|c|c|c|c|c|c|c|}
\hline & & $\begin{array}{l}\text { Protein } \\
\text { content }\end{array}$ & Oil content & Palmitic acid & Stearic acid & Oleic aicd & Linoleic acid & $\begin{array}{c}\text { Linolenic } \\
\text { acid }\end{array}$ \\
\hline \multirow{3}{*}{$\begin{array}{c}\text { Tocopherol } \\
\text { content }\end{array}$} & D1 & 0.10 & $-0.42^{* *}$ & 0.25 & 0.20 & $-0.31 *$ & 0.18 & 0.24 \\
\hline & D2 & 0.16 & -0.01 & 0.14 & $0.32 *$ & -0.22 & $0.32 *$ & 0.01 \\
\hline & D3 & $0.35 *$ & $-0.44 * *$ & 0.22 & 0.16 & -0.02 & $0.38 * *$ & $-0.52 * *$ \\
\hline
\end{tabular}

\footnotetext{
** Significant at 0.01 level of probability; *Significant at 0.05 level of probability
} 
The objective of present study was to investigate the effect of environmental conditions (temperature and photoperiod regimes) on the tocopherol accumulation in soybean seeds and to determine the correlation of tocopherol with other seed components under different environments.

The present study results showed considerable effect of environments on tocopherol content and the highest value of tocopherol content was observed under recommended sowing period of soybean for the region i.e. June sowing, suggesting that intermediate temperature and photoperiod during grain filling period leads to higher tocopherol levels whereas high or low temperatures and photoperiod during seed development stage reduces tocopherol concentration. A great variation in the total tocopherol concentration of soybean oil was observed with values ranging from as low as $530 \mathrm{ppm}$ (March sowing) to as high as $1255 \mathrm{ppm}$ (June sowing). Although, overall highest vitamin E activity has been shown by June sowing but different genotypes behaved differently in each sowing. Genotypes with highest values were present in all the three sowing date i.e March, June as well as August sowing signifying the role of genetic background of genotypes along with role of environment. The genetic variability and genotype $\mathrm{x}$ environment interactions for tocopherol content in the experimental material can be exploited for selection of soybean genotypes and environments having high tocopherol content. In this study, genotype SL (E) 38 showed highest mean of tocopherol over the environments.

Soybean is already an excellent food due to high oil and protein content. Improving the level of tocopherol (Vitamin E) in soybean oil would further increase its importance in food applications. As the tocopherol concentrations for soybean oil varies depending upon the genetic and environmental factors, understanding the effect of temperature and photoperiod on tocopherol content and relationship of tocopherol with protein, oil and fatty acids will help to identify genotypes having high tocopherol content and suitable environment for maximum activity of tocopherols. This work provides the possibility of improvement of tocopherol content by selecting suitable genotypes and growing environment. Some of the correlations of tocopherol content with other components were changed over environments due to varying effect of environment on mean and variation of these components. Correlation studies of tocopherols with other seed compositional characters under different environments will provide the information on associated changes while manipulating tocopherol content of soybean genotypes.

\section{References}

Almonor, G.O., Fenner, G.P. and Wilson, R.F. 1998. Temperature effects on tocopherol composition in soybeans with genetically improved oil quality, J. Am. Oil Chem. Soc., 75: 591-596.

AOAC. 2000: Official methods of analysis of the Association of official analytical chemists. Washington, D.C.

Boschin, G. and Arnoldi, A. 2011. Legumes are valuable sources of tocopherols. Food Chem., 127: 1199-1203.

Bramley, P.M., Elmafda, I., Kafatos, A., Kelly, F.J., Manios, Y., Roxborough, H.E., Schuch, W., Sheehy, P.J.A. and Wagner, K.H. 2000. Vitamin E (Review). J. Sci. Food Agric., 80: 913938.

Clemente, T.E. and Cahoon, E.B. 2009. Soybean Oil: Genetic approaches for modification of functionality and total content. Plant Physiol., 151: 1030-1040.

Devaraj, S. and Jialal, I. 2000. Antioxidants and Vitamins to Reduce Cardiovascular Disease. Curr. Atherosclerosis Rep., 2: 
342-351.

Dolde, D., Vlahakis, C. and Hazebroek, J. 1999. Tocopherols in breeding lines and effects of planting location, fatty acid composition, and temperature during development. J. Amer. Oil Chem. Soc., 76: 349-355.

Evans, H.M. and Bishop, K.S. 1922. On the existence of a hitherto unrecognized dietary factor essential for reproduction. Sci., 56: 650-651.

Kayden, H.J., Chow, C.K. and Bjomson, L.K. 1973. Spectrophotometric method for determination of tocopherol in red blood cells. J. Lipid Res., 14: 533-540.

Kim, H.J., Lee, H.O. and Min, D.B. 2007. Effects of prooxidant mechanisms of oxidized $\alpha$ - tocopherol on the oxidative stability of soybean oil. J. Food Sci., 72: 223-230.

Liu, K. 2000. Expanding soybean food utilization. Food Techech., 54: 46-58.

McCord, K.L., Fehr, W.R., Wang, T., Welke, G.A., Cianzio, S.R. and Schnebly, S.R. 2004. Tocopherol content of soybean lines with reduced linolenate in the seed oil. Crop Sci., 44: 772-776.

Mounts, T., Abidi, S. and Rennick, K. 1996. Effects of genetic modification on the content and composition of bioactive constituents in soybean oil. J. Amer. Oil Chem. Soc., 73: 581-586.

Rani, A., Kumar, V., Verma, S.K., Shakya, A.K. and Chauhan, G.S. 2007. Tocopherol content and profile of soybean: genotypic variability and correlation studies. J. Amer. Oil Chem. Soc., 84: 377-38.

Rizvi, S., Raza, S.T., Ahmed, F., Ahmad, A.,
Abbas, S. and Mahdi, F. 2014. The role of vitamin $\mathrm{E}$ in human health and some diseases. Sultan Qaboos Univ. Med. J., 14: 157-165.

Scherder, C.W., Fehr, W.R., Welke, G.A. and Wang, T. 2006. Tocopherol content and agronomic performance of soybean lines with reduced palmitate. Crop Sci., 46: 1286-1290.

Seguin, P., Tremblay, G., Pageau, D. and Liu, W. 2010. Soybean tocopherol concentration are affected by crop management. J. Agric. Food Chem., 58: 5495-5501.

Sharma, S. and Goyal, R. 2015. Effect of Environment on Fatty Acid Composition and Tocopherol Content in Soybean, Glycine max L Merrill. Proc. Natl. Acad. Sci. India Section B: Biol. Sci., 85: 443-450.

Shaw, E.J., Kakuda, Y. and Rajcan I. 2015. Effect of Genotype, Environment, and Genotype $\mathrm{x}$ Environment Interaction on Tocopherol Accumulation in Soybean Seed, Crop Sci., 56: 40-50.

Ujiie, A., Yamada, T., Fujimoto, K., Endo, Y. and Kitamura, K. 2005. Identification of soybean varieties with high $\alpha$-tocopherol content. Breed. Sci., 55: 123-125.

Whent, M., Hao, J., Slavin, M., Zhou, M., Song, J., Kenworthy, W. and Yu, L.L. 2009. Effect of genotype, environment, and their interaction on chemical composition and antioxidant properties of low-linolenic soybeans grown in Maryland. J. Agric. Food Chem., 57: 10163-10174.

\section{How to cite this article:}

Kuldeep Kaur, B.S. Gill, Sunita Sharma and Ashutosh Kushwah. 2017. Tocopherol Content as Affected by Different Sowing Dates and its Correlation with Other Quality Traits in Soybean [Glycine $\max$ (L.) Merrill]. Int.J.Curr.Microbiol.App.Sci. 6(5): 1492-1499. doi: https://doi.org/10.20546/ijcmas.2017.605.162 